Original Research Article

\title{
Effects of resveratrol on oxidative stress in high fat diet /streptozocin induced diabetic wistar albino rats
}

\author{
Smita Das ${ }^{1 *}$, Jayanti Prava Behera ${ }^{2}$, Y. Rojaramani ${ }^{3}$, Rashmi Ranjan Mohanty ${ }^{4}$
}

${ }^{1}$ Department of Pharmacology, IMS \& SUM Hospital, SOA (deemed to be University), Bhubaneswar, Odisha, India ${ }^{2}$ Department of Pharmacology, MKCG Medical College, Berhampur, Odisha, India ${ }^{3}$ Department of Pharmacology, SLN Medical College, Koraput, Odisha, India

${ }^{4}$ Department of Medicine, AIIMS, Bhubaneswar, Odisha, India

Received: 22 December 2018 Accepted: 29 January 2019

\section{*Correspondence to: \\ Dr. Smita Das, \\ Email: drsmitadasmohanty@ gmail.com}

Copyright: (C) the author(s), publisher and licensee Medip Academy. This is an openaccess article distributed under the terms of the Creative Commons Attribution NonCommercial License, which permits unrestricted noncommercial use, distribution, and reproduction in any medium, provided the original work is properly cited.

\begin{abstract}
Background: Diabetes mellitus is a common chronic disease. One of the pathophysiology is found to be oxidative stress. This study aims to evaluate the effect of resveratrol on oxidative stress in high fat diet (HFD)/streptozotocin induced diabetic rats.

Methods: Wistar albino rats, fed with HFD rendered diabetic with streptozotocin, were divided into 6 groups, namely the diabetic control treated with vehicle (DC), standard control which received metformin (SC), test groups treated with 5,10 , and $20 \mathrm{mg} / \mathrm{kg}$ b.w. of resveratrol and combination of half dose of metformin and resveratrol $(10 \mathrm{mg} / \mathrm{kg})(\mathrm{TC})$. A group of six normal animals served as normal control (NC), another six as HFD control. Fasting blood glucose, lipid profile and serum MDA and SOD were measured one week after induction of diabetes. The animals were then treated orally for 2 weeks after which the same parameters were repeated. The in-vivo results were analysed by one way ANOVA followed by Tukey's multiple comparison test.

Results: The DC group demonstrated a increase in the fasting blood glucose compared to NC, HFD control while a significant decrease in the fasting blood glucose was observed with $\mathrm{SC}$, Test groups $(\mathrm{p}<0.05)$ as compared to the DC group. TC showed a significant improvement in dyslipidemia compared to their baseline values $(\mathrm{p}<0.05)$. There was significant change in the serum MDA level and SOD activity.

Conclusions: Resveratrol improves oxidative stress in diabetic rats.
\end{abstract}

Keywords: Diabetes, Oxidative stress, Resveratrol

\section{INTRODUCTION}

Type 2 diabetes mellitus (T2DM) is one of the world's most common chronic diseases as changing lifestyles lead to reduced physical activity and increased obesity. ${ }^{1}$ Insulin resistance or insufficient insulin secretion not only has negative metabolic consequence but also contributes to subsequent pancreas $\beta$-cell exhaustion. ${ }^{2}$ Previous experimental study demonstrated that high fat feeding has led to insulin resistance and impaired glucose tolerance. ${ }^{3}$ Several authors suggested that increased carbohydrate in form of simple sugar like fructose ingestion may be responsible for the epidemic of obesity and the increased incidence of metabolic syndrome and 
diabetes. $^{4}$ Hyperinsulinemia is a central pathophysiological feature of NIDDM and has been shown to play a key role in the disease evolution and complications. ${ }^{5}$

Oxidative stress may be a common pathway linking diverse mechanisms of complication of DM, as several experimental animal models of diabetes induced by streptozotocin (STZ), HFD (high fat diet) with STZ and high fructose diet etc exhibit high degree of oxidative stress due to depletion of antioxidative defense system of body such as superoxide dismutase (SOD), catalase and glulathione peroxidase..$^{6,7}$

Resveratrol, a phytoalexin produced naturally by several plants when under attack by pathogens such as bacteria or fungi, has got some beneficial effects like anti-cancer, anti-inflammatory, cardioprotective, blood-sugarlowering in mouse and rat experimental models. ${ }^{8}$ Though there are various approaches are available to treat diabetes and prevent its secondary complications, herbal medications may be used as an alternative therapy as these are well tolerated.

Aims and objectives of the study was in this context, the present study was undertaken to evaluate antioxidant and hypolipidemic properties of the resveratrol which in turn may be helpful in the prevention and ultimately management of high fat diet with low dose streptozotocin induced type-2 DM model in wistar albino rats.

\section{METHODS}

Wistar albino rats of either sex weighing between 100$150 \mathrm{~g}$ were procured from National Institute of Nutrition, Hyderabad, India. They were housed in clean polypropylene cages (four rats / cage), maintained under controlled room temperature $\left(25 \pm 1^{\circ}\right)$ and with relative humidity of $45-55 \%$ under $12: 12 \mathrm{hr}$ light and dark cycle in the central animal house. They were provided with standard lab diet and water ad libitum and kept for 1 week to acclimatize with the laboratory condition before starting the experiment. Prior to the study, the study protocol was approved by I.A.E.C, M.K.C.G. Medical College, Berhampur. The study was carried out as per CPCSEA guidelines.

\section{Study design}

There were 54 wistar albino rats were grouped randomly into 9 groups and distributed 6 in each as follows:

\section{Control groups}

Gr-I: Normal pellet diet and distilled water per oral.

Gr-II: Normal pellet diet and DMSO per oral.

Gr-III: High fat diet (HFD) and DMSO per oral.

\section{Disease control}

$G r-I V$ : HFD and oral DMSO after induction of diabetes.

\section{Test groups}

$G r$-V-VII: Resveratrol in $5,10,20 \mathrm{mg} / \mathrm{kg}$ orally for 2 weeks, after induction of diabetes.

\section{Standard group}

$G r$-VIII: Metformin $(0.5 \mathrm{gm} / \mathrm{kg})$ orally for 2 weeks after induction of diabetes

\section{Combination of test and standard}

Gr-IX: Minimum effective dose of resveratrol $(10 \mathrm{mg} / \mathrm{kg})$ + half dose of metformin $(250 \mathrm{mg} / \mathrm{kg})$ orally for 2 weeks after induction of diabetes.

\section{Procedure}

The test drug resveratrol was obtained from InvivoGen, streptozotocin from Himedia Lab. and high fat diet was prepared in the Laboratory. ${ }^{3}$ The doses of standard and test drugs were selected from the different published literature. ${ }^{9,10}$ The test drug resveratrol was dissolved with DMSO before administration whereas distilled water served as vehicle for standard drug metformin.

\section{Induction of diabetes}

Diabetes mellitus was induced in overnight fasted wistar albino rats by I.P injection of single dose of freshly prepared solution of streptozotocin $(40 \mathrm{mg} / \mathrm{kg})$ which was made by dissolving with $0.1 \mathrm{M}$ Citrate buffer solution $(\mathrm{pH}$ 4.5) containing $0.9 \% \mathrm{NaCl}$ after 2 weeks of high fat diet. ${ }^{11}$ To avoid an early fatal hypoglycemia $5 \%$ glucose solution was fed on 1st day of Streptozotocin administration to all rats. The rats having fasting glucose level $\geq 200 \mathrm{mg} / \mathrm{dl}$ after $48 \mathrm{hrs}$ of administration of streptozotocin and persistent after $7^{\text {th }}$ day after administration of STZ were considered diabetic and included in the study groups. ${ }^{12}$

\section{Preparation of stock solution resveratrol}

To obtain a $20 \mathrm{mg} / \mathrm{ml}$ stock solution, $250 \mu 1 \mathrm{DMSO}$ was added to $5 \mathrm{mg}$ resveratrol powder. Solution was then vortexed until complete solubilization, aliquoted and stored at $4^{\circ} \mathrm{C}$. Required dose was obtained by dilution with distilled water as per the instruction given by the product manufacturer.

\section{Preparation of high fat diet (HFD)}

High fat diet was prepared by adding excess of coconut oil to normal diet so as to provide $42 \%$ of total calories from the fat source. ${ }^{3}$ 


\section{Estimation of biochemical parameters}

After $12 \mathrm{hr}$ fasting, about $3 \mathrm{ml}$ of blood was collected in a sterilized test tube containing EDTA through retro-orbital puncture under light ether anesthesia. Assay of different biochemical parameters like Fasting plasma glucose (GOD/POD method), plasma cholesterol (CHOD/PAP method), triglyceride(GPO / PAP method) and HDL (Peg precipitation method) were estimated by using commercially available kits (Crest Biosystem). The LDL cholesterol was calculated from the formula of Friedwald et al as given below: ${ }^{13}$

\section{LDL-C = Total cholesterol $-[$ HDL + VLDL $]$}

Where VLDL $=$ Triglyceride $/ 5$

Oxidative stress parameters like SOD activity and MDA were estimated by standard biochemical procedures. ${ }^{14,15}$

\section{Statistical analysis}

The data obtained from different parametric tests of this study like fasting plasma glucose, plasma total cholesterol, triglyceride, HDL, LDL, MDA, SOD activity were analyzed by one way ANOVA followed by Tukey's multiple comparison test. The 'P' values less than 0.05 was considered statistically significant. Graph pad prism version- 5.0 software was used for data analysis in a personal computer.

\section{RESULTS}

Table 1: Effect of resveratrol on fasting plasma glucose concentrations in HFD+STZ induced diabetic rats $(n=6)$.

\begin{tabular}{|ll|}
\hline Drug and dose & FPG $(\mathrm{mg} / \mathrm{dl})$ \\
\hline Control (DMSO) $-0.5 \mathrm{ml}$ & $90 \pm 4.26$ \\
\hline HFD + DMSO & $103.83 \pm 2.85 \#$ \\
\hline HFD+STZ + DMSO & $274.83 \pm 16.98 \$ \mathrm{a}$ \\
\hline HFD+STZ + RES $(5 \mathrm{mg} / \mathrm{kg})$ & $298.2 \pm 7.67$ \\
\hline HFD+STZ + RES $(10 \mathrm{mg} / \mathrm{kg})$ & $150 \pm 4.6^{*}$ \\
\hline HFD+STZ + RES $(20 \mathrm{mg} / \mathrm{kg})$ & $120 \pm 4.0^{* * @}$ \\
\hline $\begin{array}{l}\text { HFD+STZ + METFORMIN } \\
(500 \mathrm{mg} / \mathrm{kg})\end{array}$ & $120 \pm 2.5 * * @$ \\
\hline $\begin{array}{l}\text { HFD+STZ+MET }(250 \mathrm{mg} / \mathrm{kg}) \\
+\mathrm{RES}(10 \mathrm{mg} / \mathrm{kg})\end{array}$ & $120 \pm 3.54 * *$ \\
\hline
\end{tabular}

Data expressed as Mean \pm SE, \# $(\mathrm{p}<0.05)$ (NC vs HFD), \$ $(\mathrm{p}<0.001)(\mathrm{NC}$ Vs DC), a (HFD vs DC) $*(\mathrm{p}<0.05), * *(\mathrm{p}<0.001)$ (DC vs treatment groups), @ (p>0.05) (STD vs test drug).

It is evident from the above table that the mean fasting plasma glucose (FPG) level in HFD / streptozotocin induced diabetic rats treated with resveratrol at doses $10 \mathrm{mg} / \mathrm{kg}$ and $20 \mathrm{mg} / \mathrm{kg}$ were significantly decreased in comparison to that of disease control which is comparable to standard treated groups. But $5 \mathrm{mg} / \mathrm{kg}$ dose of resveratrol does not produce any significant effect on hyperglycemia. Minimum effective dose of resveratrol $(10 \mathrm{mg} / \mathrm{kg})$ with half dose of metformin $(250 \mathrm{mg} / \mathrm{kg})$ produced significant decrease in FPG compared with that of disease control.

Table 2: Effect of resveratrol on plasma lipid profile in HFD+STZ induced diabetic rats (n=6).

\begin{tabular}{|c|c|c|c|c|}
\hline Groups & TC (mg/dl) & TG (mg/dl) & LDL (mg/dl) & HDL (mg/dl) \\
\hline Normal control (DMSO) & $66.11 \pm 1.57$ & $82.32 \pm 1.54$ & $24.43 \pm 1.36$ & $25.22 \pm 0.72$ \\
\hline HFD+ DMSO & $81.28 \pm 3.35^{@}$ & $121.5 \pm 2.25^{@}$ & $44.31 \pm 3.69^{@}$ & $12.67 \pm 0.32^{@}$ \\
\hline $\mathrm{HFD}+\mathrm{STZ}(40 \mathrm{mg} / \mathrm{kg})+\mathrm{DMSO}$ & $125 \pm 2.69^{\$, *}$ & $216.3 \pm 2.16^{\$ *}$ & $72.44 \pm 2.71 \$ *$ & $9.27 \pm 0.28 \$ *$ \\
\hline Diabetic+ Res $(5 \mathrm{mg} / \mathrm{kg})$ & $119.9 \pm 3.27$ & $215.7 \pm 2.13$ & $67.39 \pm 3.26$ & $9.4 \pm 0.43$ \\
\hline Diabetic+ Res (10mg/ kg) & $71.3 \pm 1.95^{\#}$ & $117.7 \pm 2.21 \#$ & $25.82 \pm 6.30 \#$ & $25.77 \pm 1.44 \#$ \\
\hline Diabetic+ Res (20mg/kg) & $67.81 \pm 1.34 \#$ & $109.9 \pm 2.69 \#$ & $15.61 \pm 1.60 \#$ & $31.48 \pm 0.38 \#$ \\
\hline Diabetic+ Metformin $(500 \mathrm{mg} / \mathrm{kg})$ & 63.67士1.89\#@ & 92.78土1.23\#@ & $18.19 \pm 1.93 \#^{@}$ & $26.92 \pm 0.52 \#^{@}$ \\
\hline Diabetic+ $($ Res $10 \mathrm{mg}+$ met $250 \mathrm{mg} / \mathrm{kg})$ & $65.49 \pm 1.09 \#$ & $99.90 \pm 1.59 \#$ & $16.22 \pm 1.29 \#$ & $29.30 \pm 0.86 \#$ \\
\hline
\end{tabular}

Data are expressed as Mean \pm SEM, @ (p<0.05) (NC Vs HFD), *(P<0.001) (NC vs DC), \$ p<0.05 (HFD Vs DC), \# (p<0.05) (DC vs treatment groups), @ (p>0.05) STD vs test drug

As the Table 2 shows plasma concentration of total cholesterol (TC) was significantly increased in HFD treated group as well as in disease control group respectively compared with that of normal control treated with DMSO. The diabetic rats received resveratrol in 10 and $20 \mathrm{mg} / \mathrm{kg}$ showed significant decrease in plasma TC level respectively in comparison to disease control. The observed effects of test drug at higher doses are not significantly different from that of normal control and metformin treated group. The combined effect of minimum effective dose of resveratrol $(10 \mathrm{mg} / \mathrm{kg})$ with half dose of metformin $(250 \mathrm{mg} / \mathrm{kg})$ also showed significant decrease. The plasma concentration of TG was significantly increased in HFD treated group as well as in disease control group compared with that of normal control treated with DMSO. The diabetic rats received resveratrol in 10 and $20 \mathrm{mg} / \mathrm{kg}$ showed significant decrease in plasma TG level in comparison to disease 
control. The observed effects of test drug at higher doses are not significantly different from that of normal control and metformin treated group. The combined effect of minimum effective dose of resvertrol $(10 \mathrm{mg} / \mathrm{kg})$ with half dose of metformin $(250 \mathrm{mg} / \mathrm{kg})$ also showed significant decrease in comparison to disease control. The plasma concentration of LDL is significantly increased in HFD treated group as well as in disease control group respectively compared with that of normal control treated with DMSO. The diabetic rats received resveratrol in 10 and $20 \mathrm{mg} / \mathrm{kg}$ showed significant decrease in plasma LDL level in comparison to disease control. There were no significant difference between resveratrol treated group at 10 and $20 \mathrm{mg} / \mathrm{kg}$ and metformin treated group. The combined effect of minimum effective dose of resvertrol $(10 \mathrm{mg} / \mathrm{kg})$ with half dose of metformin $(250 \mathrm{mg} / \mathrm{kg})$ also showed significant decrease in comparison to that of disease control and is similar to normal control. The plasma concentration (HDL) is significantly decreased in HFD treated group as well as in disease control group respectively compared with that of normal control treated with DMSO. The diabetic rats received resveratrol in 10 and $20 \mathrm{mg} / \mathrm{kg}$ showed significant increase in plasma HDL level in comparison to disease control. The observed effects of test drug at higher doses are not significantly different from that of normal control and metformin treated group. The combined effect of minimum effective dose of resvertrol $(10 \mathrm{mg} / \mathrm{kg})$ with half dose of metformin $(250 \mathrm{mg} / \mathrm{kg})$ also showed significant increase in plasma HDL level compared with disease control.

Table 3: Effect of resvertrol on superoxide dismutase activity and plasma MDA level in HFD+STZ induced diabetic rats $(n=6)$.

\begin{tabular}{|c|c|c|}
\hline Groups & SOD $(\mathrm{U} / \mathrm{ml})$ & $\begin{array}{l}\text { MDA } \\
(\mathrm{nmol} / \mathrm{ml})\end{array}$ \\
\hline Control (DMSO) & $31.20 \pm 2.07$ & $3.08 \pm 0.16$ \\
\hline HFD + DMSO & $22.39 \pm 1.38^{@}$ & $4.58 \pm 0.16^{@}$ \\
\hline $\begin{array}{l}\text { DC (HFD+STZ- } \\
40 \mathrm{mg} / \mathrm{kg})+\mathrm{DMSO}\end{array}$ & $14.78 \pm 0.86 *$ & $6.79 \pm 0.23^{*, \#}$ \\
\hline $\begin{array}{l}\text { Diabetic +Resv } \\
(5 \mathrm{mg} / \mathrm{kg})\end{array}$ & $15.07 \pm 0.86$ & $6.41 \pm 0.24$ \\
\hline $\begin{array}{l}\text { Diabetic +Resv } \\
(10 \mathrm{mg} / \mathrm{kg})\end{array}$ & $32.67 \pm 1.11 \$ \$ \$$ & $3.95 \pm 0.23 \$$ \\
\hline $\begin{array}{l}\text { Diabetic +Resv } \\
(20 \mathrm{mg} / \mathrm{kg})\end{array}$ & $34.89 \pm 1.92 \$ \$ \$$ & $3.62 \pm 0.15 \$$ \\
\hline $\begin{array}{l}\text { Diabetic + Met } \\
(500 \mathrm{mg} / \mathrm{kg})\end{array}$ & $26.97 \pm 1.03 \$$ & $2.95 \pm 0.10 \$$ \\
\hline $\begin{array}{l}\text { Diabetic + (Resv } \\
10 \mathrm{mg} / \mathrm{kg}+\text { Met } \\
250 \mathrm{mg} / \mathrm{kg})\end{array}$ & $25.38 \pm 1.19 \$$ & $3.45 \pm 0.16 \$$ \\
\hline
\end{tabular}

Data expressed as Mean $\pm \mathrm{SEM},{ }^{\circledR} \mathrm{p}<0.01$ (Normal control Vs HFD control), ${ }^{*} p<0.001$ (NC Vs DC),\# p<0.05(HFD Vs DC), \$ $\mathrm{p}<0.05, \$ \$ \$ \mathrm{p}<0.001$ (Diabetic group Vs treatment group)

As the Table shows plasma SOD activity was significantly decreased in HFD control as well as in disease control respectively compared with normal control received DMSO. Groups treated with resveratrol
$10 \mathrm{mg} / \mathrm{kg}$ and $20 \mathrm{mg} / \mathrm{kg}$ produced significant increase in plasma SOD activity respectively which were similar with that of metformin treated group and not significantly different from normal control. The combined effect of minimum effective dose of resveratrol with half effective dose of metformin showed significant increase in plasma SOD activity compared with disease control and is similar to that of group treated with metformin alone. The plasma MDA level was significantly increased in HFD control as well as in disease control respectively compared with normal control received DMSO. Groups treated with resveratrol $10 \mathrm{mg} / \mathrm{kg}$ and $20 \mathrm{mg} / \mathrm{kg}$ produced significant decrease in plasma MDA level respectively which are similar with that of metformin treated group and not significantly different from normal control. The combined effect of minimum effective dose of resveratrol with half effective dose of metformin showed significant decrease in plasma MDA level compared with disease control and is similar to that of group treated with metformin alone.

\section{DISCUSSION}

The present study was undertaken to evaluate the effect of resveratrol on lipid profile and oxidative stress in term of blood glucose profile of HFD and low dose STZ $(40 \mathrm{mg} / \mathrm{kg}$ ) model of T2DM in wistar albino rats. The effect of resveratrol in different doses like 5, 10 and $20 \mathrm{mg} / \mathrm{kg}$, were studied by estimating biochemical parameters (FPG, lipid profile, MDA and SOD activity) in plasma. The results were compared with that of standard drug (metformin).

Wistar albino rats were selected for this study as the rodents (rats/mice) are standardized experimental animals both for behavioral study and used for the effect of a candidate compound on intermediary metabolism in liver muscle and adipose tissue with subsequent effects on metabolic blood parameters like glucose, lipids, etc. There are reports suggesting streptozotocin induced diabetic wistar rats showing significantly higher fasting plasma glucose, higher area under curve of an oral glucose tolerance test, and higher lipid abnormalities in comparison to other strains. ${ }^{16}$

The dose and route of streptozotocin for induction of diabetes were taken from the previous published articles ${ }^{2}$. HFD was prepared by adding excess of coconut oil $(42 \% \mathrm{v} / \mathrm{w})$ to standard laboratory diet and fed to the experimental animals for 2 weeks prior to STZ. ${ }^{3}$ Dose and route of resveratrol were chosen from the similar type of published work. ${ }^{10}$

For induction T2DM, a single low dose of STZ at $40 \mathrm{mg} / \mathrm{kg}$ body weight was injected after 2 weeks of HFD feeding. High doses of STZ (>40 mg/kg body weight i.e. $60-80 \mathrm{mg} / \mathrm{kg}$ ) is well known to be taken by pancreatic $\beta$ cells via GLUT2 and to induce severe damages of pancreatic $\beta$-cells, mimicking Type-I DM. ${ }^{17}$ But the combination of HFD and low doses of STZ resulted in characteristic of type-2DM where insulin resistance plays 
a major role in pathophysiology leading to various metabolic alterations like increased blood glucose level, hyperinsulinemia, and dyslipidemia. ${ }^{12}$ Oxidative stress is one of the major predisposing factors in this experimental model. So, in this present study HFD/ low dose STZ model was selected.

Early treatment with antidiabetic dugs and lifestyle modification such as losing weight, exercising, and watching the diet are often recommended for prevention and control of diabetes and related complications. Though there are a good number of pharmaceutical products (medicines) developed day by day to control the disease but most of them are not free from dangerous unwanted effects. Thus, there has been a growing interest in herbal remedies that can be introduced into the general population with the least side effects and the maximal preventive outcome. ${ }^{18}$ Resveratrol which is used as nutritional supplements for some of its beneficial effect, are not cleared. In this present study, rats of different control groups administered with distilled water and DMSO did not produce any significant change in the mean fasting plasma glucose level and also there is no significant change between control group and HFD group. ${ }^{2}$

Disease control group received HFD/ STZ produced significant increase in plasma glucose level. ${ }^{2}$ Resveratrol treated groups in doses 10 and $20 \mathrm{mg} / \mathrm{kg}$ for a period of 14 days produced significant decrease in FPG in comparison to disease control and remained within the normal range. ${ }^{19}$ This effect is similar to standard drug metformin. The combined effect of resveratrol with metformin showed significant decrease in plasma glucose level which is comparable with normal control group. ${ }^{20}$

Resveratrol in doses 10 and $20 \mathrm{mg} / \mathrm{kg}$ produced significant decrease in TC, TG and LDL level with increase in HDL level in a dose dependant manner in comparison to disease control which showed beneficial effect on dyslipidemia due to diabetes. This result of the present study corroborates with observations made by Shahi et al. ${ }^{19}$ It also noted that metfomin alone as well as in combination with resveratrol showed significant improvement in plasma lipid profile in diabetic rats which is comparable with normal control.

The result of this study showed significant increase in plasma SOD activity and decrease in plasma MDA level in resveratrol treated groups in of 10 and $20 \mathrm{mg} / \mathrm{kg}$ dose level. The standard drug metformin alone as well as combination with resveratrol showed significant improvement in plasma SOD activity and MDA level in diabetic rats and is comparable with normal control group. $^{21}$

\section{CONCLUSION}

Resveratrol, a phytochemical present in grape skin, red wine, purple grape juice, peanuts, and some berries, is commonly used as nutritional supplement and proved in some studies for its beneficial effects like antiinflammatory, blood sugar lowering in some mouse and rat experimental models. Though some of its effects are proved in few clinical studies, its effects are not yet fully established for its use in therapy. Therefore, the present study has been undertaken to evaluate the potential role of resveratrol against hyperglycemia, dyslipidemia, oxidative stress HFD/STZ induced T2DM in wistar albino rats.

The result of this study revealed that resveratrol at a dose of 10 and $20 \mathrm{mg} / \mathrm{kg}$ showed significant antihyperglycemic effect, favourable effect on lipid profile with improvement in oxidative stress parameter which are comparable with that of metformin. These effects are may be due to its enhancement of peripheral glucose utilization by increasing insulin sensitivity. Though it is being used as nutritional supplement, this study result may be due to action on sirtuin 1 which was proved by other similar studies.

On the basis of these observed results of this present study, it can be concluded that resveratrol can be a better candidate to control T2DM and may prevent its complications like diabetic neuropathy. Also along with other oral antidiabetic agents like metformin, resveratrol can have potential adjuvant value. By this the dose of antidiabetic agent can be reduced and may limit the burden of ADR related to that particular drug. Therefore it can be suggested that more and more animal studies and further clinical trials are needed to establish its clinical use in future.

\section{Funding: No funding sources}

Conflict of interest: None declared

Ethical approval: The study was approved by the Institutional Ethics Committee

\section{REFERENCES}

1. Yadav NK, Sathian B, Kalai RS. Assessment of Diabetes Mellitus in India and Nepal. Web Med Central Biochem. 2012;3(6),WMC003544.

2. Jung JY, Lim Y, Moon MS, Kim JY, Kwon O. Onion peel extracts ameliorate hyperglycemia and insulin resistance in high fat diet/streptozotocin induced diabetic rats. Nutr Metab (Lond). 2011;8:18.

3. Buettner R, Parhofer KG, Woenckhaus $\mathrm{M}$, et al. Defining high fat diet rat models: metabolic and molecular effects of different fat types. J Molecular Endocrinol. 2006;36(3):485-501.

4. Bray GA, Nielsen SJ, Popkin BM. Consumption of high fructose corn syrup in beverages may play a role in the epidemic of obesity. Am J Clin Nutr. 2004;79:537-43.

5. Shalam Md, Harish MS, Farhana SA. Prevention of dexamethasone and fructose-induced insulin resistance in rats by $\mathrm{SH}-01 \mathrm{D}$, a herbal prepara 7 tion, Indian J Pharmacol. 2006;38(6):419-22. 
6. Bais SK, Shrirao SG, Shende G, Kochar NI, Jiddewar A, Chandewar AV. Evaluation of effects of rutin on oxidative stress in diabetic rat. Int $\mathrm{J}$ Pharm Pharm Sci. 2012;4(Suppl 5):140-5.

7. Genet S, Kale RK, Baquer NZ. Alterations in antioxidant enzymes and oxidative damage in experimental diabetic rat tissue; Effect of vanadate and fenugreek (Trigonella faenum graeoum). Mol Cell Biochem. 2002;236:7-12.

8. Su HC, Hung LM, Chen JK. Resveratrol, a red wine antioxidant, possesses an insulin-like effect in streptozotocin-induced diabetic rats. Am J PhysiolEndocrinol Metabol. 2006;290:1.

9. Kaur S, Cheema, Fariborz, Rashid-Kolvear. Streptozotocin induced increase in cholesterol ester transfer protein (CETP) and its reversal by insulin in transgenic mice expressing human CETP Can. J Physiol Pharmacol. 2003;81(10):997-1004

10. Rivera L, Mor'on R, Zarzuelo A, Galisteo M. Longterm resveratrol administration reduces metabolic disturbances and lowers blood pressure in obese Zucker rats. Biochem Pharmacol. 2009;77(6):105363.

11. Chang KJ. Effect of taurine and beta alanine on morphological changes of pancreas in streptozotocin induced diabetic rats. Adv Exp Med Biol. 2000;483:571-7.

12. Lu HE, Jian $\mathrm{CH}$, Chen SF, Chen TM. Hypoglycaemic effects of fermented mycelium of Paecilomyces farinosus (G30801) on high-fat fed rats with streptozotocin-induced diabetes, Indian J Med Res. 2010;131:696-701.

13. Friedewald WT, Levy RI, Frederickson DS. Estimation of the concentration of low density lipoprotein cholesterol in plasma, without use of preparative ultracentrifuge. Clin Chem. 1972;18:499. 502.

14. Dhale LK, Hill EG, Holman RT. The thiobarbituric acid reaction and the auto-oxidation of poly- unsaturated fatty acid methyl ester. Arch. Biochem. Biophysics. 1962;98:253-61.

15. Kakkar P, Das B, Viswanathan PN. A Modified Spectrophotometric Assay of Superoxide Dismutase. J Biochem Biophy. 1984:21:330.

16. Rodrigues B, Can MC, Kong J, Goyal RK, McNeil JH. Strain differences in susceptibility to streptozotocin induced diabetes-effect on hypertriglyceridemia and cardiomyopathy. Cardiovasc Res. 1997;534:199.

17. Szkudelski T. The mechanism of alloxan or streptozotocinaction in B cells of the rat pancreas. Physiol Res. 2001;50(6):537-46.

18. Pradeepa R, Rema M, Vignesh J, Deepa M, Deepa R, Mohan V. Prevalence and risk factors for diabetic neuropathy in an urban south Indian population: The Chennai Urban Rural Epidemiology Study (CURES55). Diabet Med. 2008;25:407-12.

19. Shahi MM, Haidari F, Shiri MR. Comparison of effect of resveratrol and vanadium on diabetes related dyslipidemia and hyperglycemia in streptozotocin induced diabetic rats. Adv Pharma Bulletin. 2011;1(2):81-6.

20. U.K. Prospective Diabetes Study Group. Eeffect of intensive blood glucose-control with metformin on complications in overweight patients with type2 diabetes (UKPDS). Lancet. 1998;352:854-65.

21. Kumar A, Kaundal RK, Iyer S, Sharma SS. Effect of resveratrol on nerve functions, oxidative stress and DNA fragmentation in experimental diabetic neuropathy. Life Sci. 2007;80(13):1236-44.

Cite this article as: Das S, Behera JP, Rojaramani Y, Mohanty RR. Effects of resveratrol on oxidative stress in high fat diet /streptozocin induced diabetic wistar albino rats. Int J Basic Clin Pharmacol 2019;8:482-7. 